\title{
Aqueous Photocatalytic Oxidation of Lignin and Humic Acids with Supported $\mathrm{TiO}_{2}$
}

\author{
Elina Portjanskaja, ${ }^{1}$ Sergei Preis, ${ }^{2}$ and Juha Kallas ${ }^{2}$ \\ ${ }^{1}$ Department of Chemical Engineering, Tallinn University of Technology, Ehitajate tee 5, Tallinn 19086, Estonia \\ ${ }^{2}$ Department of Chemical Technology, Lappeenranta University of Technology, P.O. Box 20, 53851 Lappeenranta, Finland
}

Received 19 February 2006; Accepted 19 February 2006

The photocatalytic oxidation (PCO) of UV-irradiated aqueous solutions containing humic acids and lignin was studied. The photocatalyst $\mathrm{TiO}_{2}$ was attached to buoyant hollow glass microspheres and glass plates. A maximum oxidation efficiency as low as 1.1 and $2.54 \mathrm{mg} \mathrm{W}^{-1} \mathrm{~h}^{-1}$ for humic acids and lignin, respectively, was achieved in neutral and alkaline media with $25 \mathrm{gm}^{-2}$ of the buoyant catalyst. In acidic media, efficiency was even lower. The photocatalytic efficiency with the photocatalyst attached to glass plates was about 3 to 4 times higher than that for the buoyant catalyst. Ferrous ions added to acidic solutions did not increase the rate of PCO of humic acids. However the addition of $\mathrm{Fe}^{2+}$ ions, up to $0.05 \mathrm{mM}$, to the lignin solution leads to a dramatic increase, about 25\%, in PCO efficiency. A further increase in ferrous ion concentration results in a decrease in the PCO efficiency of lignin. Proceeding most likely by a radical mechanism, the efficiency of PCO of humic acids did not benefit from an excessive presence of hydroxyl radical promoters, such as hydrogen peroxide, although the reaction rate increased. However, PCO of lignin in the acidic medium, where $\mathrm{OH}$-radical formation is suppressed, benefited from the introduction of hydrogen peroxide due to promoted radical formation.

Copyright (c) 2006 Elina Portjanskaja et al. This is an open access article distributed under the Creative Commons Attribution License, which permits unrestricted use, distribution, and reproduction in any medium, provided the original work is properly cited.

\section{INTRODUCTION}

Lignin and its fragments of complex aromatic structure form the major part of the waste from the pulp and paper industry [1]. Lignin is resistant to natural decomposition processes: its lifetime in aqueous media in nature is about 200 days. Natural decomposition of lignin results in the formation of toxic phenolics, aldehydes, ketones, methanol, and carbonic acids [2]. This toxic behaviour is suspected of being a reason for the depressed immunity of human populations consuming water from polluted sources, especially in the vicinity of pulp and paper plants, and, as a result, for the twofold increase in endocrine systematic diseases observed for population consuming the polluted water even after it having passed conventional water treatment procedure [3]. The current strategies of wastewater treatment are ineffective against lignin: only large molecules of lignosulfonates, but not their fragments, can be removed with coagulants [4]. White rot fungi-based biological oxidation systems may be a prospective solution, although their application in nonsterile conditions is problematic [5]. Concerning potable water treatment, increased chlorination should not be considered due to the formation of much more toxic chlorinated substances.
Humic substances (HS) are water-soluble compounds with a molecular weight of several hundreds to a few hundred thousands. Being mainly the final products of plant tissue decomposition, HS are resistant to biological oxidation. They are not toxic, although the intensive colour given by HS to water may irritate customers and make water inappropriate for use in laundering, paper and beverages production, the food industry, and so forth [6]. However, the colouring of water is not the only, and by far not the most significant negative property of HS. Humics contain a branched carbon skeleton with a high degree of aromatic character and with a large percentage of the molecular weight incorporated in functional groups, mostly carboxylic and phenolic ones. The latter make HS bond aqueous toxics such as heavy metals and organic pollutants (pesticides, insecticides, herbicides, etc.) thus making the toxics difficult to remove by simple methods [6]. Furthermore, HS are well-known precursors of carcinogenic and mutagenic trihalomethanes generated in conventional water treatment procedures, including chlorination $[7,8]$. Humic substances formation in landfill leachate should be the cause of great concern because of the high heavy metal and organic toxics content. Curiously, HS are not formed from lignin in the latter's natural aqueous 
decomposition process. However, HS are abundantly present in landfill leachate due to anaerobic decomposition of lignocellulose [9]. This may be explained by the thermophilic phase of composting, at which white-rot fungi do not survive and cannot take part in lignin degradation [10].

The abatement strategies for HS include both conventional and advanced methods, such as coagulation, adsorption on various sorbents, nanofiltration and oxidation variations. All these methods have certain drawbacks, such as sludge accumulation, material transportation and treatment for regeneration, membrane fouling, and high capital investment costs.

Photocatalytic oxidation (PCO) has shown easy degradation of the studied substances $[11,12]$ and could, therefore, be a possible solution due to the cheap solar energy source and freedom from the drawbacks listed above. The PCO of organic pollutants is based on the photochemical production of an electron-hole pair in a solid semiconductor under irradiation by light of energy greater than its optical band. Photocatalytic oxidation is believed to have a dual mechanism of oxidation: (1) the adsorption of the pollutant by the surface of the titanium dioxide is followed by a direct subtraction of the pollutant's electrons, that is, oxidation, with positively charged holes; (2) oxidation takes place at the catalyst surface or in its vicinity with hydroxyl radicals [13].

Photocatalytic studies have usually employed various photocatalysts, mostly titanium dioxide, in the suspended or the attached form. A major problem with using unsupported photocatalysts in a photoreactor is that only the thin exterior layer of the unsupported photocatalyst actually absorbs UV light [14]. In addition, separation of the fine catalyst powder from the treated water may present a problem [15]. Possible solutions to this involve utilization of a thin layer of titanium dioxide coated on a variety of supports, for example, glass rings, aluminium sheets, silica, ceramics, magnesia, and so forth. Titanium dioxide attached to buoyant hollow glass microspheres and horizontally positioned glass plates was studied here.

Photocatalytic oxidation with a titanium dioxide photocatalyst was studied for the removal of lignin and humic acids (HA) under variable parameters, such as the initial concentration of pollutant and $\mathrm{pH}$. Many studies have demonstrated that the presence of hydrogen peroxide as an $\mathrm{OH}$ radical promoter improved the performance of photocatalytical degradation [16-18], therefore the addition of $\mathrm{H}_{2} \mathrm{O}_{2}$ was also studied here.

Several previous studies have reported higher PCO rates following the addition of small amounts of ferrous [16, 17, $19]$ and some other multivalent cations [20,21]. Our previous studies showed the positive role of ferrous ions, abundantly present in waters under anoxic reductive conditions, such as groundwater or landfill leachate, at low concentrations in the efficiency of PCO of methyl tert-butyl ether and 2-ethoxyethanol [22]. The results of the more detailed investigation, given here, extend knowledge of the influence of iron ions on pollutants of various types and show the complex character of the dependence of the PCO efficiency on the concentration of iron ions.

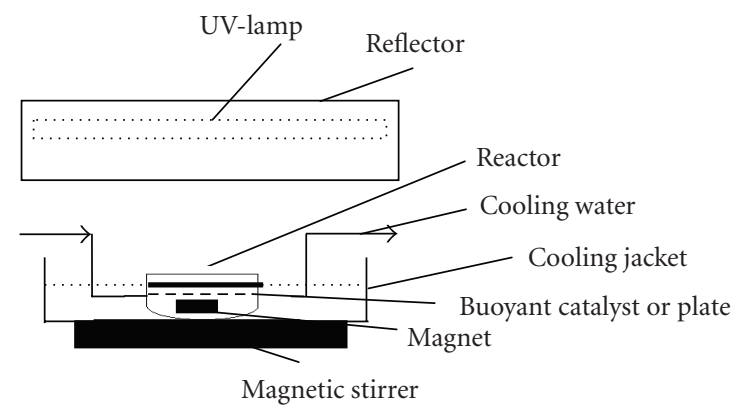

FIgURE 1: The photocatalytic oxidation experimental set-up.

\section{EXPERIMENTAL SECTION}

Two $200 \mathrm{~mL}$ simple batch reactors with an inner diameter $100 \mathrm{~mm}$ (evaporation dishes), aperture $40 \mathrm{~m}^{2} \mathrm{~m}^{-3}$, thermostatted at $20 \pm 1^{\circ} \mathrm{C}$ and mechanically agitated with magnetic stirrers were used in the PCO experiments: the reactor used for the PCO was called "active" and the other, containing no photocatalyst, was called "reference." Both reactors were exposed to identical experimental conditions. The samples from the active reactor were compared to the reference samples to avoid complications caused by water evaporation. A UV-light source, Phillips TLD 15 W/05 lowpressure luminescent mercury UV-lamp with emission maximum at $360 \mathrm{~nm}$, was positioned horizontally over the reactors (Figure 1), providing irradiance of about $0.7 \mathrm{~mW} \mathrm{~cm}^{-2}$ measured by the optical radiometer UVX at a distance corresponding to the level of the free surface of the reactor.

The experiments were conducted with synthetic solutions of chemicals purchased from Aldrich. The substrates were prepared in concentrations of $10 \mathrm{mg} \mathrm{L}^{-1}$ of sodium salt of HA and $100 \mathrm{mg} \mathrm{L}^{-1}$ of lignin alkali solution, if not specified differently, by direct dissolution in distilled water. The final $\mathrm{pH}$ was 7 and 8 , respectively. The $\mathrm{pH}$ value of the solutions was adjusted with $2 \mathrm{M}$ solutions of sulphuric acid or sodium hydroxide. The treatment time was $24 \mathrm{~h}$. All the experiments were carried out three times under identical conditions; the average deviation of data in parallel experiments did not exceed $5 \%$.

The experiments were performed using Degussa P25 titanium dioxide. The supported catalyst option was $\mathrm{TiO}_{2}$ attached to buoyant hollow glass microspheres and to the surface of the glass plate $\left(0.7 \mathrm{mg} \mathrm{cm}^{-2}\right)$. The hollow glass microspheres used in this study had an average diameter of 60 to $70 \mu \mathrm{m}$ and a density $0.27 \mathrm{~g} \mathrm{~cm}^{-3}$ (the product of LP-ImpEx, Estonia). Titanium dioxide was attached to the surface of the microbeads by the thermal method [23]: equal volumes of dry microspheres and aqueous suspension of titanium dioxide with a concentration of $1 \mathrm{~g} \mathrm{~L}^{-1}$ were mixed by stirring and sonication for $30 \mathrm{~min}$. The microspheres were then separated from the mixture by filtration with a membrane filter, heated to dryness at $120^{\circ} \mathrm{C}$ and calcinated at a temperature of $300^{\circ} \mathrm{C}$ for $4 \mathrm{~h}$. This procedure was repeated six times, which was found to be the optimum number of attachment operations [24]. The amount of $\mathrm{TiO}_{2}$ attached to the microspheres 
was estimated by gravimetric method and ranged around $10 \mathrm{mg}$ per $\mathrm{g}$ of microspheres. The amount of buoyant catalyst used in the experiments was $25 \mathrm{~g} \mathrm{~m}^{-2}$. Analogously, $\mathrm{TiO}_{2}$ was attached to the surface of the glass plate (one side) by multiple submerging of the plate in the $\mathrm{TiO}_{2}$ suspension with subsequent drying after each submersion. $\mathrm{TiO}_{2}$ attached to glass plates, submerged horizontally in the solution to be treated at a depth from 5 to $10 \mathrm{~mm}$, was used in the PCO experiments.

In the case with the buoyant catalyst, samples taken during the experiment were separated from the catalyst before analysis. For HA, colour was determined with the spectrophotometer $\mathrm{HACH} \mathrm{DR/2010} \mathrm{at} 455 \mathrm{~nm}$. An absorbance at $254 \mathrm{~nm}$ was measured by Spectronic Unicam spectrophotometer $(\operatorname{He} \lambda \operatorname{ios} \beta)$. Both indices were correlated with the content of HA or lignin by calibration curves. The lignin concentration was measured with the photometric method developed by HACH Co. Solutions, namely sodium carbonate solution and tannin-lignin reagent, containing sodium molybdate and sodium tungstate (VI), react with lignin forming blue-coloured intermediates. After $25 \mathrm{~min}$ of reaction time the colour intensity was measured. Aldehydes, as PCO by-products of lignin, were quantitatively determined by the methods described by Evans and Dennis [25]. The analysis was performed by measuring an optical density of a $5 \mathrm{ml}$ centrifuged sample at $630 \mathrm{~nm}$, to which $0.5 \mathrm{ml}$ of sulphuric acid, $1 \mathrm{ml}$ of sodium arsenite solution, and $1 \mathrm{ml}$ of 3-methylbenzolthiazol-2-one hydrazone hydrochloride $(\mathrm{MBTH})$ solution were added. The samples were immersed in a boiling water bath for $6 \mathrm{~min}$. Following that, the samples were cooled to room temperature and $1 \mathrm{~mL}$ of iron (III) chloride - sulphamic acid reagent was added. The samples were allowed to stand for 20 min before measurements were taken. Calibration was done with acetaldehyde.

\section{RESULTS AND DISCUSSION}

The performance of PCO with artificial radiation sources was characterised by the process efficiency $E$. The efficiency $E$ is defined as the decrease in the amount of HA or lignin divided by the amount of energy reaching the surface of the treated sample [26]:

$$
E=\frac{\Delta c \cdot V \cdot 1000}{I \cdot s \cdot t}
$$

where $E$ is the photocatalytic oxidation efficiency in $\mathrm{mg}$ $\mathrm{W}^{-1} \mathrm{~h}^{-1} ; \Delta c$ denotes the decrease of pollutants concentration in $\mathrm{mg} \mathrm{L}^{-1} ; V$ depicts the volume of the sample to be treated in $\mathrm{L} ; I$ is irradiation intensity in $\mathrm{mW} \mathrm{cm}^{-2}$; $s$ denotes the solution irradiated plane surface area in $\mathrm{cm}^{2}$; and $t$ depicts the treatment time in hours.

It was found that PCO led to a decrease in HA and lignin concentrations over time. The catalyst presence was essential, as no decrease in concentration was observed in the absence of titanium dioxide.

\subsection{Influence of pollutant initial concentration}

Photocatalytic oxidation of pollutants with initial concentrations of HA ranging from 5 to $50 \mathrm{mg} \mathrm{L}^{-1}$ at $\mathrm{pH} 7$ and lignin from 35 to $400 \mathrm{mg} \mathrm{L}^{-1}$ at $\mathrm{pH} 8$ with $\mathrm{TiO}_{2}$ attached to hollow glass microspheres gave a close to linear dependence of the PCO efficiency on the pollutant concentration: the efficiency of HA PCO increased from $0.2 \mathrm{mg} \mathrm{W}^{-1} \mathrm{~h}^{-1}$ at $5 \mathrm{mg} \mathrm{L}^{-1}$ to $3.4 \mathrm{mg} \mathrm{W}^{-1} \mathrm{~h}^{-1}$ at $50 \mathrm{mg} \mathrm{L}^{-1}$ and for lignin these numbers were $2.0 \mathrm{mg} \mathrm{W}^{-1} \mathrm{~h}^{-1}$ at $35 \mathrm{mg} \mathrm{L}^{-1}$ and $6.5 \mathrm{mg} \mathrm{W}^{-1} \mathrm{~h}^{-1}$ at $400 \mathrm{mg} \mathrm{L}^{-1}$. This indicates that the reactions under experimental conditions may be described by first-order or Langmuir-Hinshelwood equations. The difference in $\mathrm{pH}$ for the HA and lignin solutions was due to the fact that the commercially available lignin exhibited a slightly alkaline reaction whereas the HA solution remained neutral. Aromatic compounds are generally UV absorbers, which should lead to a decrease in the UV transparency of the solution and thus to a decrease in PCO efficiency. However, we found that, within the experimental limits, PCO efficiency increased with increased concentration of pollutant. The optimum concentration corresponding to the maximum efficiency was not found within the studied interval of pollutant concentrations.

A linear increase in the aldehyde concentration with increasing initial concentration of lignin was observed: the aldehyde concentration increased from 20 to $90 \mu \mathrm{M}$ within the lignin concentration limits of 35 to $400 \mathrm{mg} \mathrm{L}^{-1}$. This fact may show that the PCO reactions proceed with the formation of by-products not only on the surface of $\mathrm{TiO}_{2}$ and its vicinity, but also in the bulk solution: no immediate total mineralisation was thus observed; some oxidation products are either desorbed from the $\mathrm{TiO}_{2}$ surface or formed in the solution. The formation of aldehydes in PCO of HA was not noticed, probably because the concentrations of HA were too low for aldehyde measurements.

A decrease in $\mathrm{pH}$ was observed in the experiments with lignin, which was probably due to the formation of carboxylic groups and carbonic acids as a result of PCO; a reaction known to go via formation of aldehydes. In the PCO of the aqueous solution containing $100 \mathrm{mg} \mathrm{L}^{-1}$ of lignin, for example, $\mathrm{pH}$ changed from 8.37 to 6.45 in $24 \mathrm{~h}$. However, $\mathrm{pH}$ of photocatalytically treated HA solutions behaved differently: $\mathrm{pH}$ remained neutral when the experiment started at $\mathrm{pH}$ 7.0. Furthermore, in experiments with the $\mathrm{pH}$ initially adjusted above or below 7.0, for example to 5.0 or to 9.0 , a tendency to approximate $\mathrm{pH} 7.0$ was seen during the PCO. Since molecules of HA contain nitrogen atoms, the authors suppose that the behaviour of $\mathrm{pH}$ can be explained by the transformation of HA structural nitrogen to ammonia. The decrease in $\mathrm{pH}$ of the PCO-treated HA basic aqueous solutions can, presumably, be explained by the escape of free ammonia and formation of carboxylic acids, whereas the increase in $\mathrm{pH}$ in acidic media is a result of partial binding of acidity with free ammonia formed in the solution, that is, HA under oxidation exhibit a buffering capacity.

\section{2. $\mathrm{pH}$ and $\mathrm{H}_{2} \mathrm{O}_{2}$ influence}

The results of PCO of HA and lignin solutions are presented in Figure 2 and show that the process efficiency depends on $\mathrm{pH}$. Both substances showed maximum PCO efficiency 


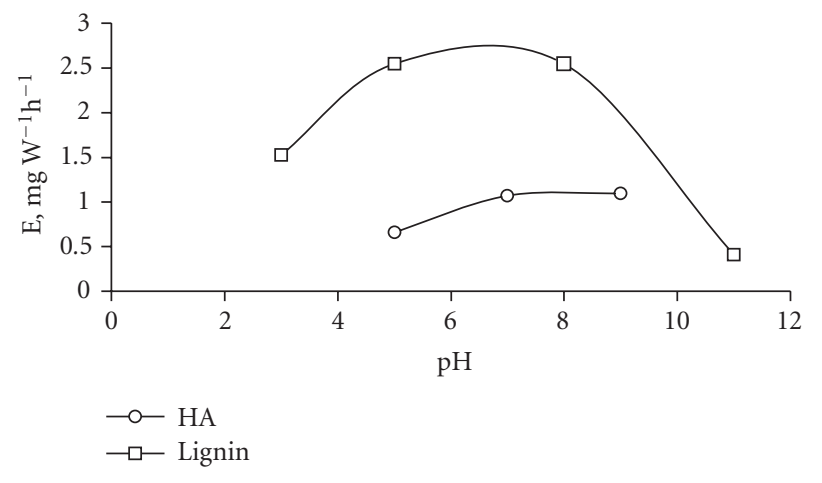

FIgURE 2: The dependence of the photocatalytic oxidation efficiency $E$ of humic acids and lignin on $\mathrm{pH}$ : initial concentration of humic acids 10 and lignin $100 \mathrm{mg} \mathrm{L}^{-1}$, buoyant catalyst plane surface concentration $25 \mathrm{~g} \mathrm{~m}^{-2}$; treatment time $24 \mathrm{~h}$.

under neutral and slightly basic media conditions. The HA PCO efficiency at pH between 7.0 and 9.0 with the buoyant photocatalyst was equal to $1.1 \mathrm{mg} \mathrm{W}^{-1} \mathrm{~h}^{-1}$, and at $\mathrm{pH} 5.0$ this number averaged $0.67 \mathrm{mg} \mathrm{W}^{-1} \mathrm{~h}^{-1}$. The decrease of PCO efficiency under alkaline conditions could be explained by the effect of charges repulsion between both negatively charged lignin molecules and $\mathrm{TiO}_{2}$ particles (see below) and accumulation of $\mathrm{OH} \cdot-$ radical scavenging carbonate ions under alkaline conditions.

The relationship between pollutant adsorption on the $\mathrm{TiO}_{2}$ surface and the PCO efficiency at different $\mathrm{pH}$ and in the presence of radical promoters may indicate the mechanism prevailing in oxidation of the pollutant. For example, we found that the best adsorption of $\mathrm{HA}$ on $\mathrm{TiO}_{2}$ was observed at $\mathrm{pH} 3.0$ (Figure 3(a)): the equilibrium surface concentration was about $120 \mathrm{mg} \mathrm{g}^{-1} \mathrm{TiO}_{2}$ at $25^{\circ} \mathrm{C}$, with a gradual decrease of the surface concentration with growing $\mathrm{pH}$ to approximately $30 \mathrm{mg} \mathrm{g}^{-1} \mathrm{TiO}_{2}$ at $\mathrm{pH} 7.0$ and 9.0 [24]. However, the maximum PCO efficiency for HA was observed at the lowest adsorption $\mathrm{pH}$ range, in neutral and alkaline media, which may point to the prevailing oxidation of HA with $\mathrm{OH}$--radicals, abundantly formed at elevated $\mathrm{pH}$ (Figure 2). Low PCO efficiency in acidic media could be explained by less effective direct oxidation of the pollutant with positively charged holes due to the complex molecular structure of the adsorbed pollutant; oxidation of HA with $\mathrm{OH} \cdot-$ radicals appears to be more successful: the radicals are formed in neutral and alkaline media at a higher rate due to the abundant presence of $\mathrm{OH}$-ions as $\mathrm{OH}$--radicals precursors. In acidic media, the formation of $\mathrm{OH}$-radicals is poor due to low $\mathrm{OH}$-ions concentration.

The isotherms for lignin adsorption on the $\mathrm{TiO}_{2}$ surface at different $\mathrm{pH}$ are shown in Figure 3(b). One can see that lignin adsorption depends on $\mathrm{pH}$ similarly to HA: an acidic medium is favourable for adsorption, whereas in alkaline solutions lignin practically does not adsorb on the $\mathrm{TiO}_{2}$ surface. Nevertheless, the $\mathrm{pH}$ range of good adsorption of lignin does not coincide with the $\mathrm{pH}$ range of high $\mathrm{PCO}$ efficiency (Figure 2), which also may indicate the prevailing role of $\mathrm{OH} \cdot$-radicals in PCO of lignin.
Another way to estimate the contribution of $\mathrm{OH} \cdot-$ radicals to $\mathrm{PCO}$ of $\mathrm{HA}$ and lignin is to study the influence of a well-known $\mathrm{OH}$--radical source, hydrogen peroxide. Resulting from the addition of $\mathrm{H}_{2} \mathrm{O}_{2}$, the increased PCO rate may be attributed to a decrease in electron-hole recombination rate because of the conduction band electrons scavenged by hydrogen peroxide or superoxide ions and generation of $\mathrm{OH} \cdot$-radicals [27].

Several researchers have previously investigated the effect of hydrogen peroxide on the photocatalytic oxidation of organic contaminants. Beneficial effects of the addition of $\mathrm{H}_{2} \mathrm{O}_{2}$ have been reported for the photocatalytic treatment of pesticides, dissolved organic matter in the effluent of the pulp and paper mill industry [28], and other organic contaminants. Positive effects were also reported by Bandala et al. [29] for the photocatalytic degradation of the pesticide Aldrin using nonconcentrated and concentrated solar radiation. On the other hand, Dillert et al. [30] found that, in most cases, the addition of $\mathrm{H}_{2} \mathrm{O}_{2}$ caused a reduction in the degradation rates of 2,4,6-trinitrotoluene and 1,3,5trinitrobenzene at various initial $\mathrm{pH}$ values (3-11) compared to those of the $\mathrm{UV} / \mathrm{TiO}_{2}$ system. The authors hypothesized that this effect could be due to the competition of $\mathrm{H}_{2} \mathrm{O}_{2}$ with the nitroaromatic contaminants for conduction band electrons.

In our experiments, hydrogen peroxide was added to the

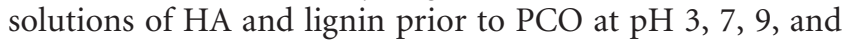
11 in amounts from 0.7 to $50 \mathrm{mM}$. In all cases the addition of $\mathrm{H}_{2} \mathrm{O}_{2}$ led to the oxidation of HA in both the PCO-treated sample and the reference. Thus, an increase in the sum reaction rate was observed, however the efficiency of PCO decreased since a part of the HA was reacting directly with $\mathrm{H}_{2} \mathrm{O}_{2}$ in the reference sample. The higher the $\mathrm{H}_{2} \mathrm{O}_{2}$ dose, the lower the efficiency observed, that is, photocatalytic decomposition of $\mathrm{H}_{2} \mathrm{O}_{2}$ with additional hydroxyl radicals' generation did not result in more energy-efficient decomposition of HA.

The addition of hydrogen peroxide to the lignin solutions enhanced the degradation rate considerably in the acidic medium (Figure 4). The rate improvement is due to $\mathrm{OH}$ radical generation subsequent to the conduction band electron scavenging with hydrogen peroxide:

$$
\mathrm{e}^{-}+\mathrm{H}_{2} \mathrm{O}_{2} \longrightarrow \mathrm{HO} \cdot+\mathrm{OH}^{-} .
$$

In neutral media, the PCO efficiency gradually and slightly decreased with increasing $\mathrm{H}_{2} \mathrm{O}_{2}$ concentration. This can be explained by competition of $\mathrm{H}_{2} \mathrm{O}_{2}$ with the contaminant for adsorption sites on titanium dioxide. In alkaline media one can see a sudden decrease in the PCO efficiency at an $\mathrm{H}_{2} \mathrm{O}_{2}$ concentration of $1 \mathrm{mM}$. This fact can be explained by the scavenging of the valuable $\mathrm{OH}$--radicals by hydrogen peroxide and the forming of the much weaker oxidanthydroperoxide radical $\mathrm{HO}_{2} \cdot[31]$ :

$$
\mathrm{H}_{2} \mathrm{O}_{2}+\mathrm{HO} \cdot \longrightarrow \mathrm{H}_{2} \mathrm{O}+\mathrm{HO}_{2} \cdot
$$

With further growth of $\mathrm{H}_{2} \mathrm{O}_{2}$ concentration, the secondary formation of $\mathrm{OH} \cdot-$ radicals from the hydroperoxide radical is 


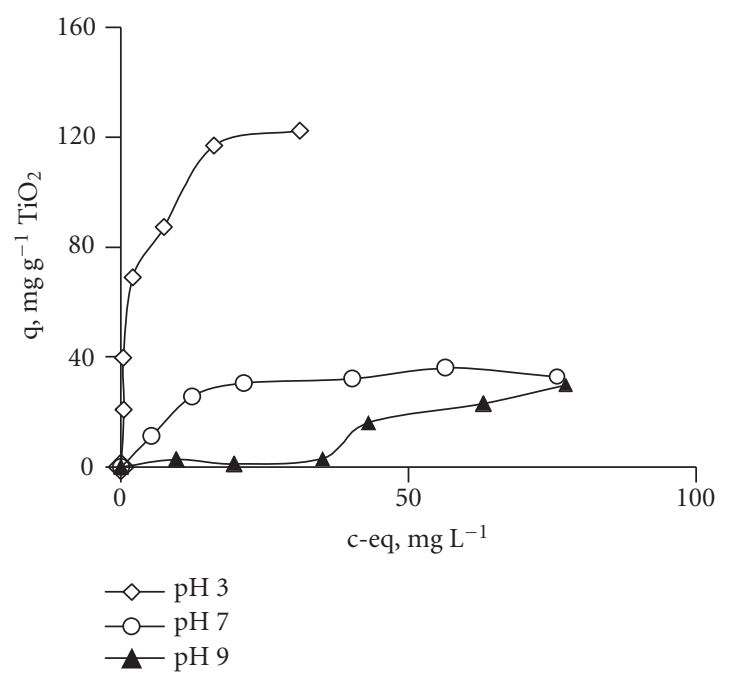

(a)

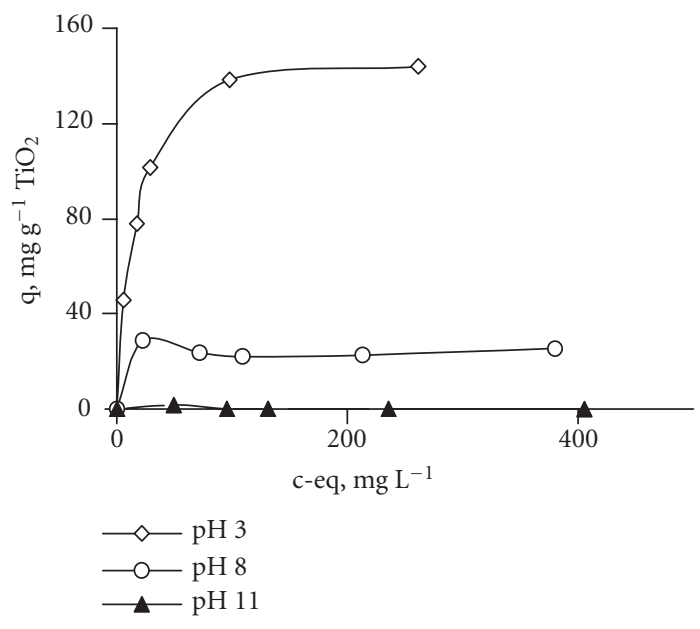

(b)

FIgURE 3: Effect of $\mathrm{pH}$ on the adsorption isotherms at $25^{\circ} \mathrm{C}$ for (a) humic acids and (b) lignin on the $\mathrm{TiO}_{2}$ surface: $\mathrm{c}$-eq is the equilibrium concentration of pollutant in the solution and $\mathbf{q}$ is the amount of pollutant adsorbed by $\mathrm{TiO}_{2}$.

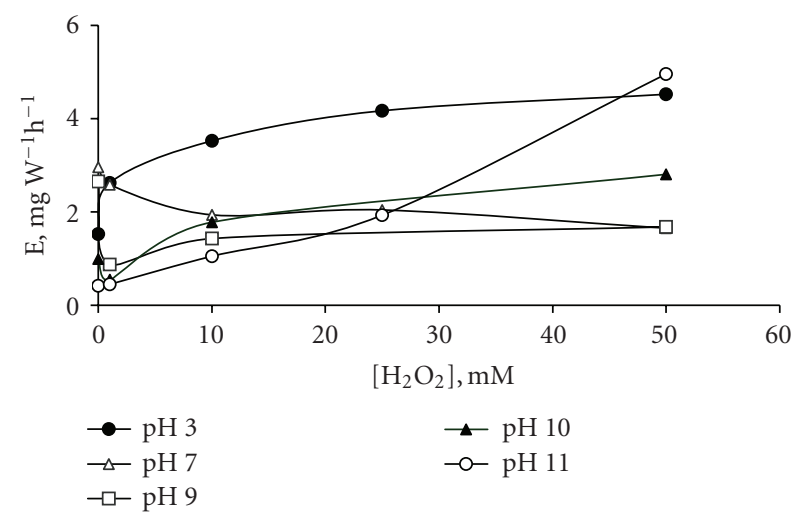

FIGURE 4: The dependence of the PCO efficiency of lignin on hydrogen peroxide concentration at different $\mathrm{pH}$ : initial concentration of lignin $100 \mathrm{mg} \mathrm{L}^{-1}$, buoyant catalyst plane surface concentration $25 \mathrm{~g} \mathrm{~m}^{-2}$; treatment time $24 \mathrm{~h}$.

likely to prevail:

$$
\mathrm{HO}_{2} \cdot+\mathrm{H}_{2} \mathrm{O}_{2} \longrightarrow \mathrm{HO} \cdot+\mathrm{H}_{2} \mathrm{O}+\mathrm{O}_{2} .
$$

This may lead to the increase in the PCO efficiency with increasing $\mathrm{H}_{2} \mathrm{O}_{2}$ concentration observed in Figure 4 for alkaline media. Abundant presence of $\mathrm{OH}$-ions in the solution at high $\mathrm{pH}$ levels results in massive $\mathrm{OH}$--radical formation in both direct $\mathrm{PCO}$ oxidation of $\mathrm{OH}$-ions and secondary formation of $\mathrm{OH}$--radicals from hydrogen peroxide, which explains increasing PCO efficiency with increasing $\mathrm{pH}$.

\subsection{Influence of ferrous ions}

A drastic increase in PCO efficiency of lignin at low, below $0.05 \mathrm{mM}$, concentrations of $\mathrm{Fe}^{2+}$ (Figure 5(b)) coincides well with observations made earlier for other aqueous pollutants [22] and could be explained by the decrease in recombination rate between positively charged holes and conductivity band electrons, which is considered a PCO limitation stage. Conductivity electrons may be scavenged by ferrous ions adsorbed on the $\mathrm{TiO}_{2}$ surface at their higher oxidation, that is, ferric stage, extending the lifetime and thus the oxidation performance of the positively charged holes.

In contrast to many substances, in the experiments with HA the addition of $\mathrm{Fe}^{2+}$ up to $0.1 \mathrm{mM}$ leads solely to a sharp decrease in PCO efficiency on the photocatalyst attached to the glass plate from 4.15 to $1.65 \mathrm{mg} \mathrm{W}^{-1} \mathrm{~h}^{-1}$ (Figure 5(a)). A further increase in $\mathrm{Fe}^{2+}$ ions concentration up to $0.3 \mathrm{mM}$ resulted in stabilisation of the PCO efficiency value at $1.6 \mathrm{mg} \mathrm{W}^{-1} \mathrm{~h}^{-1}$. A similar dependency pattern was observed with the buoyant photocatalyst, although the efficiency rates were lower. Since the influence of ferrous ion was studied in acidic media, where $\mathrm{OH} \cdot$-radicals give little contribution to PCO performance, the observed inhibitive effect of ferrous ions on the PCO efficiency for HA could be explained by the complications in HA adsorption: not only do $\mathrm{Fe}^{2+}$-ions block the adsorption sites at the $\mathrm{TiO}_{2}$ surface, but also the partial chelation of carboxylic and phenolic groups of the humic molecules with the $\mathrm{Fe}^{2+}$-ions may obstruct their adsorption at the $\mathrm{TiO}_{2}$ surface. Under these circumstances, the prolonged lifetime of positively charged holes may weaken due to obstructions in the adsorption of chelated humic molecules [32].

In contrast to $\mathrm{HA}$, chelation of lignin with $\mathrm{Fe}^{2+}$ ions was probably not pronounced due to the small number of carboxylic groups in the structure of the lignin molecule. Ferrous ions thus only occupy the adsorption sites on the surface of $\mathrm{TiO}_{2}$ without further complications for the adsorption of chelated iron complex molecules. This made the PCO efficiency increase from 5.6 to $7.0 \mathrm{mg} \mathrm{W}^{-1} \mathrm{~h}^{-1}$ with increasing 


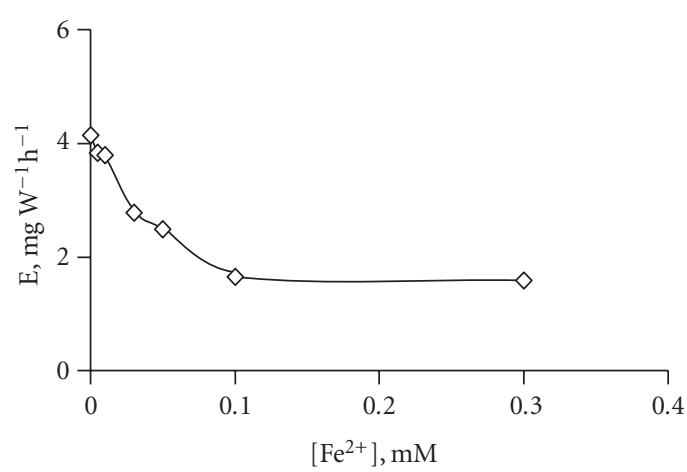

(a)

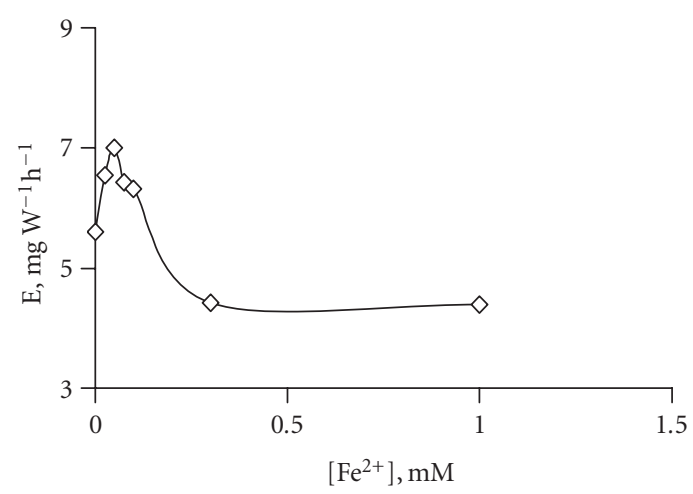

(b)

Figure 5: The efficiency of PCO of (a) humic acids, $10 \mathrm{mg} \mathrm{L}^{-1}$, and (b) lignin, $100 \mathrm{mg} \mathrm{L}^{-1}$, with $\mathrm{TiO}_{2}$ attached to the glass plate, $0.7 \mathrm{mg} \mathrm{cm}^{-2}$; $\mathrm{pH} 3$; treatment time $24 \mathrm{~h}$.

concentration of ferrous ions from 0 to $0.05 \mathrm{mM}$. The decrease in PCO efficiency from 7.0 to $4.4 \mathrm{mg} \mathrm{W}^{-1} \mathrm{~h}^{-1}$ with further increase in ferrous ion concentration is, presumably, caused by the blockage of absorption sites by metallic ions. The lack of precipitates observed with lignin at concentrations up to $200 \mathrm{mg} \mathrm{L}^{-1}$ in the presence of ferrous ions indirectly confirmed the absence of chelation with lignin molecules. Humic acids, however, easily precipitate in the presence of ferrous ion at concentrations slightly above the experimental limits of this study.

There is an observation made during the study which cannot be easily explained by the authors at this stage of the research: aldehydes observed as PCO by-products of lignin were not traced in PCO treated solutions of lignin in the presence of ferrous ions. This may indicate a difference in oxidation pathways in the presence and absence of $\mathrm{Fe}^{2+}$, however, further research is necessary to explain the observation in detail.

\section{CONCLUSIONS}

The photocatalytic oxidation efficiency increased with increasing concentrations of humic acids and lignin. Maximum efficiency, observed with aromatic compounds, was not achieved during PCO of HA and lignin within the experimental limits.

The highest PCO efficiency for both substances was observed in neutral and slightly basic media, despite the fact that the best adsorption was in acidic media. This means that the oxidation of HA and lignin may proceed preferably by the radical mechanism.

Photocatalytic oxidation of HA and lignin benefited from the introduction of hydrogen peroxide in the acidic medium due to promoted $\mathrm{OH} \cdot-$-radical formation. The increased PCO efficiency in alkaline media may be also explained by enhanced formation of $\mathrm{OH}$--radicals. Together with the fact that there was no direct mineralisation of lignin on the photocatalyst surface-aldehydes were observed in the bulk solution-it becomes evident that $\mathrm{OH}$--radicals play a major role in the PCO of lignin.
Ferrous ions did not increase the rate of HA PCO. However the addition of $\mathrm{Fe}^{2+}$ ions to the lignin solution, up to $0.05 \mathrm{mM}$, leads to the drastic increase of PCO efficiency. A further increase in ferrous ion concentration results in a decrease in PCO efficiency of lignin.

\section{ACKNOWLEDGMENT}

The financial support from the Academy of Finland, Project 208134, and the Estonian Science Foundation, Grant 5899, is acknowledged.

\section{REFERENCES}

[1] D. S. Agryropoulos and S. B. Menachem, Biotechnology in Pulp and Paper Industry, edited by K. Eriksson, Springer, Berlin, Germany, 1997.

[2] L. Cotrim da Cunha, L. Serve, F. Gadel, and J.-L. Blazia, "Lignin-derived phenolic compounds in the particulate organic matter of a French Mediterranean river: seasonal and spatial variations," Organic Geochemistry, vol. 32, no. 2, pp. 305-320, 2001.

[3] U. Hamm, H.-J. Öller, and K. Kuwan, "Endocrine substances in paper mill effluents," International Paperworld, no. 1, pp. 45-48, 2005.

[4] F. B. Dilek and C. F. Gökçay, "Treatment of effluents from hemp-based pulp and paper industry: I - waste characterization and physico-chemical treatability," Water Science and Technology, vol. 29, no. 9, pp. 161-163, 1994.

[5] T. Mester and M. Tien, "Oxidation mechanism of ligninolytic enzymes involved in the degradation of environmental pollutants," International Biodeterioration and Biodegradation, vol. 46, no. 1, pp. 51-59, 2000.

[6] S. E. Manahan, Environmental Chemistry, Lewis, New York, NY, USA, 1994.

[7] B. R. Eggins, F. L. Palmer, and J. A. Byrne, "Photocatalytic treatment of humic substances in drinking water," Water Research, vol. 31, no. 5, pp. 1223-1226, 1997.

[8] G.-S. Wang, C.-H. Liao, and F.-J. Wu, "Photodegradation of humic acids in the presence of hydrogen peroxide," Chemosphere, vol. 42, no. 4, pp. 379-387, 2001. 
[9] M. A. Sánchez-Monedero, A. Roig, J. Cegarra, and M. P. Bernal, "Relationships between water-soluble carbohydrate and phenol fractions and the humification indices of different organic wastes during composting," Bioresource Technology, vol. 70, no. 2, pp. 193-201, 1999.

[10] M. Tuomelaa, M. Vikmanb, A. Hatakka, and M. Itävaara, "Biodegradation of lignin in a compost environment: a review," Bioresource Technology, vol. 72, no. 2, pp. 169-183, 2000.

[11] M. Bekbolet, A. S. Suphandag, and C. S. Uyguner, "An investigation of the photocatalytic efficiencies of $\mathrm{TiO}_{2}$ powders on the decolourisation of humic acids," Journal of Photochemistry and Photobiology A: Chemistry, vol. 148, no. 1-3, pp. 121-128, 2002.

[12] A. Dahm and L. A. Lucia, "Titanium dioxide catalyzed photodegradation of lignin in industrial effluents," Industrial and Engineering Chemistry Research, vol. 43, no. 25, pp. 79968000, 2004.

[13] A. L. Linsebigler, G. Lu, and J. T. Yates Jr., "Photocatalysis on $\mathrm{TiO}_{2}$ surfaces: principles, mechanisms, and selected results," Chemical Reviews, vol. 95, no. 3, pp. 735-758, 1995.

[14] A. Sirisuk, C. G. Hill Jr., and M. A. Anderson, "Photocatalytic degradation of ethylene over thin films of titania supported on glass rings," Catalysis Today, vol. 54, no. 1, pp. 159-164, 1999.

[15] S. Sakthivel, M. V. Shankar, M. Palanichamy, B. Arabindoo, and V. Murugesan, "Comparative study of $\mathrm{TiO}_{2}$ supported on alumina and glass beads," Journal of Photochemistry and Photobiology A: Chemistry, vol. 148, no. 1-3, pp. 153-159, 2002.

[16] J. Araña, O. G. Díaz, J. M. Doña Rodríguez, et al., "Role of $\mathrm{Fe}^{3+} / \mathrm{Fe}^{2+}$ as $\mathrm{TiO}_{2}$ dopant ions in photocatalytic degradation of carboxylic acids," Journal of Molecular Catalysis A: Chemical, vol. 197, no. 1-2, pp. 157-171, 2003.

[17] M. Mrowetz and E. Selli, "Effects of iron species in the photocatalytic degradation of an azo dye in $\mathrm{TiO}_{2}$ aqueous suspensions," Journal of Photochemistry and Photobiology A: Chemistry, vol. 162, no. 1, pp. 89-95, 2004.

[18] M. Qamar, M. Saquib, and M. Muneer, "Photocatalytic degradation of two selected dye derivatives, chromotrope $2 \mathrm{~B}$ and amido black 10B, in aqueous suspensions of titanium dioxide," Dyes and Pigments, vol. 65, no. 1, pp. 1-9, 2005.

[19] V. Vamathevan, H. Tse, R. Amal, G. Low, and S. McEvoy, "Effects of $\mathrm{Fe}^{3}+$ and $\mathrm{Ag}^{+}$ions on the photocatalytic degradation of sucrose in water," Catalysis Today, vol. 68, no. 1-3, pp. 201208, 2001.

[20] V. Brezová, A. Blazková, E. Borosová, M. Čeppan, and R. Fiala, "The influence of dissolved metal ions on the photocatalytic degradation of phenol in aqueous $\mathrm{TiO}_{2}$ suspensions," Journal of Molecular Catalysis A: Chemical, vol. 98, no. 2, pp. 109-116, 1995.

[21] D. Beydoun, H. Tse, R. Amal, G. Low, and S. McEvoy, "Effect of copper(II) on the photocatalytic degradation of sucrose," Journal of Molecular Catalysis A: Chemical, vol. 177, no. 2, pp. 265-272, 2002.

[22] D. Klauson and S. Preis, "The influence of ferrous ions on the efficiency of aqueous photocatalytic oxidation of 2-ethoxy ethanol," International Journal of Photoenergy, vol. 7, no. 4, pp. 175-180, 2005.

[23] N. B. Jackson, C. M. Wang, Z. Luo, et al., "Attachment of $\mathrm{TiO}_{2}$ powders to hollow glass microbeads. Activity of the $\mathrm{TiO}_{2}-$ coated beads in the photoassisted oxidation of ethanol to acetaldehyde," Journal of the Electrochemical Society, vol. 138, no. 12, pp. 3660-3664, 1991.

[24] E. Portjanskaja, M. Krichevskaya, S. Preis, and J. Kallas, "Photocatalytic oxidation of humic substanceswith $\mathrm{TiO}_{2}$-coated glass micro-spheres," Environmental Chemistry Letters, vol. 2, no. 3, pp. 123-127, 2004.

[25] W. H. Evans and A. Dennis, "Spectrophotometric determination of low levels of mono-, di- and triethylene glycols in surface waters," The Analyst, vol. 98, no. 1172, pp. 782-791, 1973.

[26] S. Preis, M. Krichevskaya, Y. Terentyeva, A. Moiseev, and J. Kallas, "Treatment of phenolic and aromatic amino compounds in polluted waters by photocatalytical oxidation," Journal of Advanced Oxidation Technologies, vol. 5, no. 1, pp. 77-84, 2002.

[27] I. A. Balçiglu and Y. Inel, "Photocatalytic degradation of organic contaminants in semiconductor suspensions with added $\mathrm{H}_{2} \mathrm{O}_{2}$," Journal of Environmental Science and Health, vol. 31, no. 1, pp. 123-138, 1996.

[28] A. E. H. Machado, J. A. de Mirandaa, R. F. de Freitas, et al., "Destruction of the organic matter present in effluent from a cellulose and paper industry using photocatalysis," Journal of Photochemistry and Photobiology A: Chemistry, vol. 155, no. 13, pp. 231-241, 2003.

[29] E. R. Bandala, S. Gelover, M. T. Leal, C. Arancibia-Bulnes, A. Jimenez, and C. A. Estrada, "Solar photocatalytic degradation of Aldrin,” Catalysis Today, vol. 76, no. 2-4, pp. 189-199, 2002.

[30] R. Dillert, I. Fornefett, U. Siebers, and D. Bahnemann, "Photocatalytic degradation of trinitrotoluene and trinitrobenzene: influence of hydrogen peroxide," Journal of Photochemistry and Photobiology A: Chemistry, vol. 94, no. 2-3, pp. 231-236, 1996.

[31] B. Sun, M. Sato, and J. S. Clements, "Optical study of active species produced by a pulsed streamer corona discharge in water," Journal of Electrostatics, vol. 39, no. 3, pp. 189-202, 1997.

[32] D. Klauson, S. Preis, E. Portjanskaja, A. Kachina, M. Krichevskaya, and J. Kallas, "The influence of ferrous/ferric ions on the efficiency of photocatalytic oxidation of pollutants in groundwater," Environmental Technology, vol. 26, no. 6, pp. 653-661, 2005. 


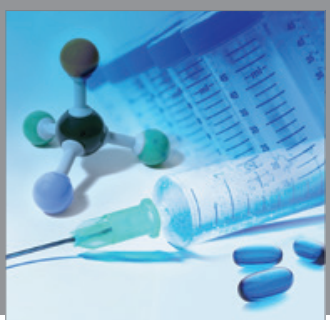

International Journal of

Medicinal Chemistry

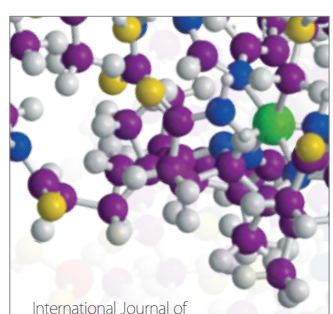

Carbohydrate Chemistry

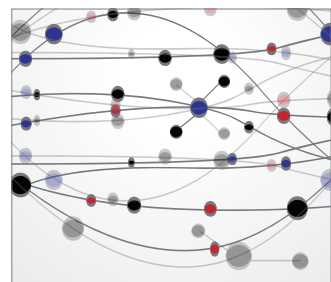

The Scientific World Journal
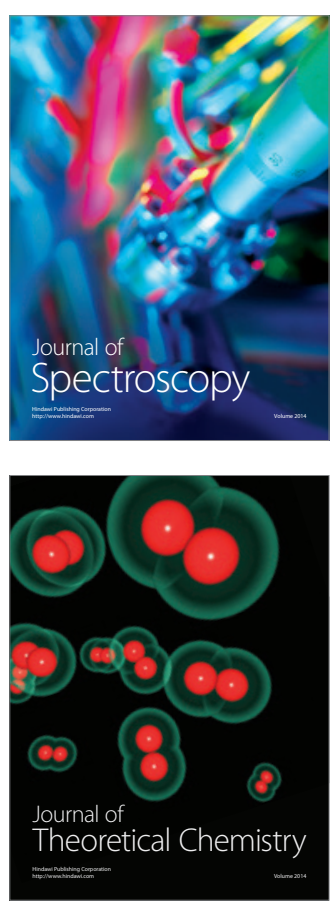
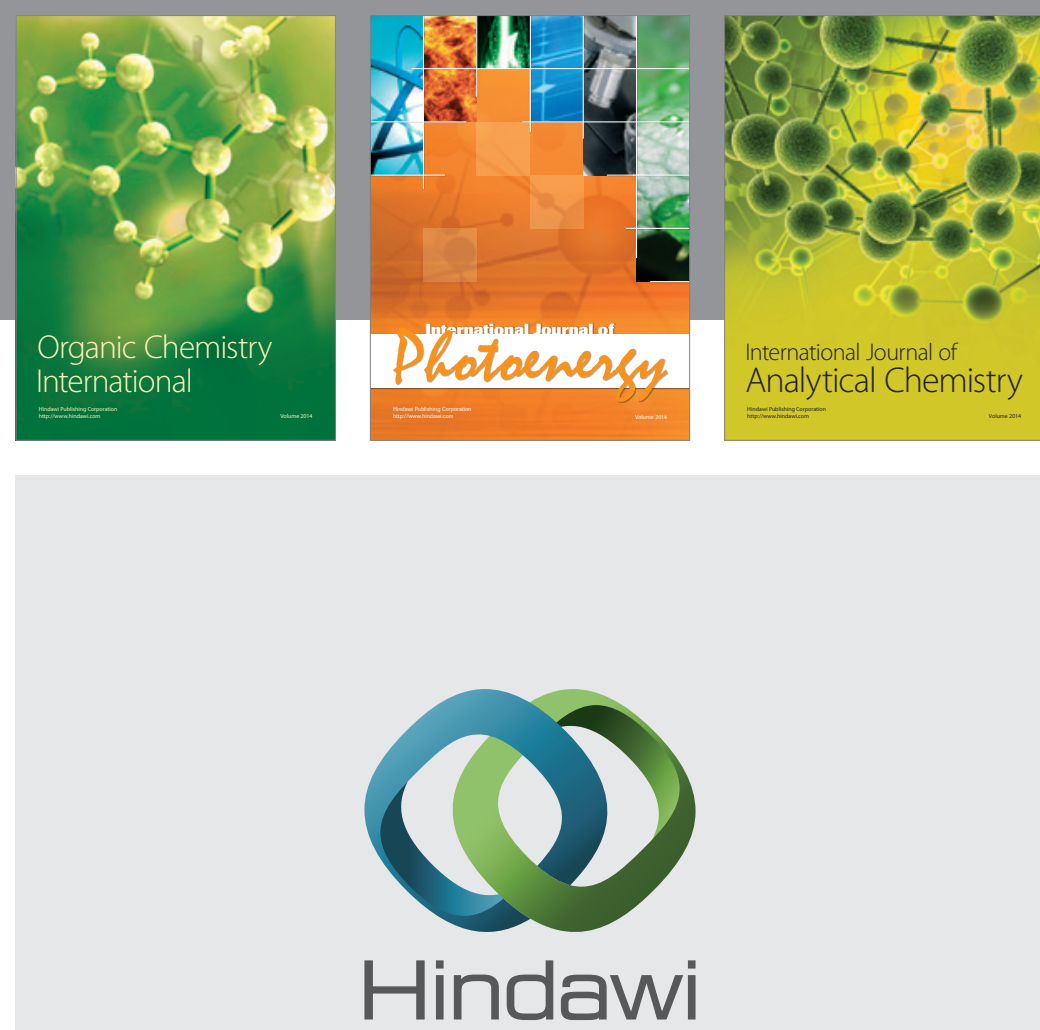

Submit your manuscripts at

http://www.hindawi.com
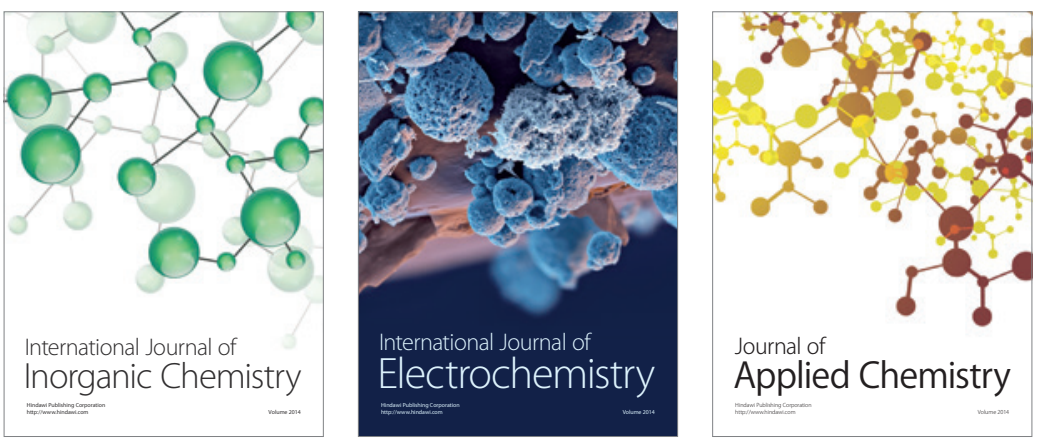

Journal of

Applied Chemistry
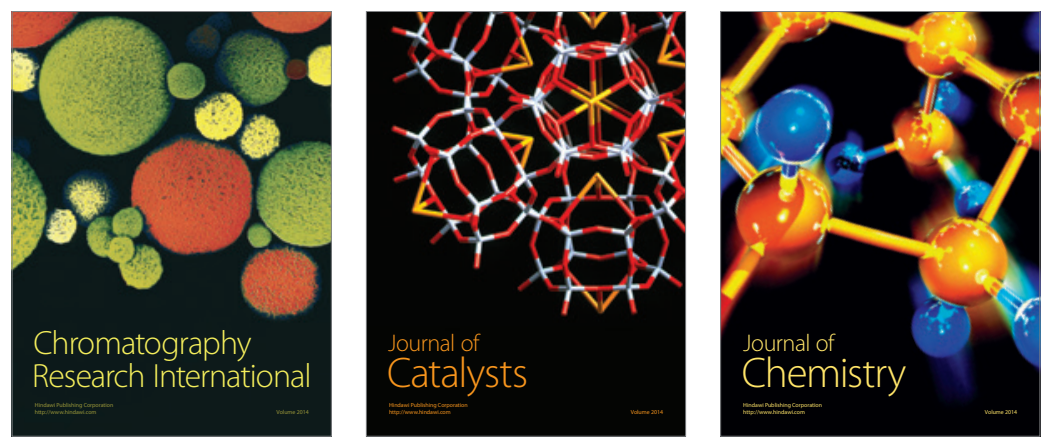
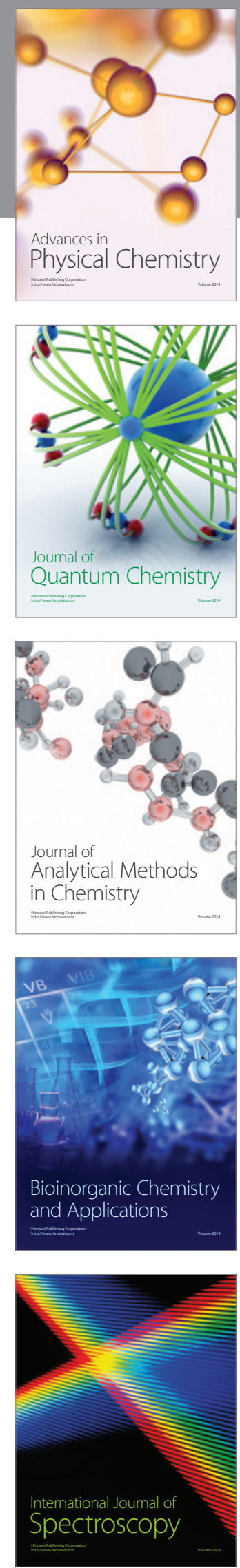